\title{
TEMA 4 -2018: Terapia génica en el arsenal de terapéutica de la enfermedad oncológica
}

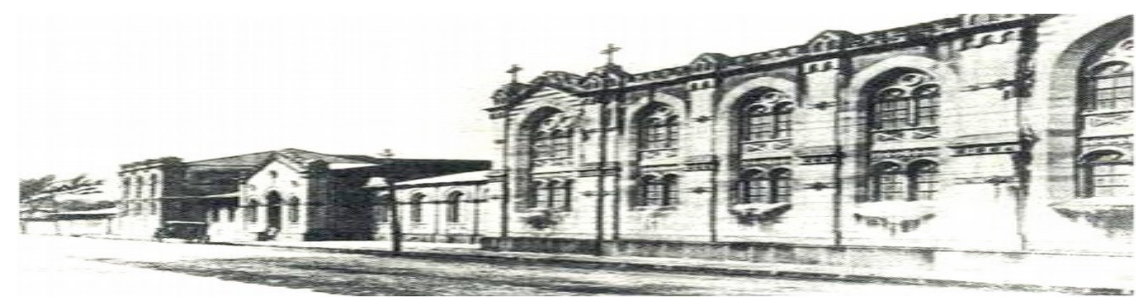

Haspital San quan de Dios. San José. Casta Rica. Fundada en 1845

Recibido: $\quad 13 / 12 / 2017$

Aceptado: $\quad 15 / 01 / 2018$

Morales González, Fernando ${ }^{1}$

${ }^{1} 1$ Estudiante de Maestría en Ciencias Médicas, Sistema de Estudios de Postgrado de la Universidad de Costa Rica. Médico Residente en Medicina Interna, Sistema de Estudios de Postgrado de la Universidad de Costa Rica- Hospital San Juan de Dios. San José, Costa Rica. Fmorales@medicos.cr

\section{RESUMEN}

La terapia génica es una modalidad de intervención que, aunque se planteó inicialmente para la modificación de enfermedades metabólicas con modificación exógena únicamente, conforme avanza la investigación presenta una gama increíble de potenciales mecanismos de acción y dianas terapéuticas principalmente en el manejo de la enfermedad oncológica como tal.

\section{PALABRAS CLAVE}

Enfermedades Metabólicas; Terapia Génica; Oncología; CRISP-CAS9. Fuente: NLM, MeSH.

\section{ABSTRACT}

Gene therapy is an intervention modality that although it was initially proposed for the modification of metabolic diseases with exogen modification only as the research progresses, it presents an incredible range of potential mechanisms of action and therapeutic targets mainly in the management of the oncological disease.

\section{KEY WORDS}

Metabolic Diseases, Genetic Therapy, Oncology, Crisp-Cas9 Source: NLM, MeSH.

\section{INTRODUCCIÓN}

En la concepción y evolución de la terapia genética (TG) se había caracterizado en la misma como principal uso de esta modalidad la entrega de copias adicionales de un gen para la corrección directa de los defectos genéticos endógenos con la identificación de genes basados en la recombinación homóloga con la sustitución de un tracto de $\mathrm{ADN}$ genómico portador de una mutación por uno que lleva la secuencia normal, administrado exógenamente(1).

El abordaje clásico está enfocado en suplementar la carencia de defectos enzimáticos en enfermedades metabólicas. Los primeros modelos implicaron aumento por injerto ex vivo de células modificadas para expresar moléculas relacionadas con síndrome de Lesch-Nyhan, deficiencia de ADA, deficiencia de receptor de 
LDL, deficiencia de alfa1 antitripsina, hemofilia, enfermedad de Gaucher, entre otras(2).

Sin embargo nuestro conocimiento se ha ampliado hacia manipular ADN o ARN para el tratamiento o la prevención de enfermedades humanas. Las estrategias en general de la terapia génica son diversas, como rectificar, reemplazar o eliminar los genes culpables de las enfermedades genéticas, produciendo mutaciones incapacitantes en los genomas de los patógenos para combatir las enfermedades infecciosas o inducir mutaciones somáticas terapéuticas o protectoras(3).

\section{DISCUSIÓN}

Hasta el 2016 se han reportado 2356 ensayos clínicos de terapia génica aprobados llevandose a cabo o completados en el mundo. Los adenovirus, los retrovirus y los plásmidos desnudos han sido los vectores de transferencia génica más comunes en los ensayos clínicos. Se han llevado a cabo 1517 ensayos clínicos con el objetivo de tratar varios tipos de cáncer, que marcan el cáncer como la afección más común que actualmente se utiliza con la terapia génica(4).

Aproximadamente dos tercios de los casos clínicos de la terapia genética se ha enfocado en el tratamiento de varios tipos de cáncer(5).

Es importante destacar que en el marco jurisdiccional, al menos en los Estados Unidos, las terapias génicas están sujetas a la supervisión de dos agencias federales dentro del Departamento de Salud y Servicios Humanos: la Administración de Alimentos y Medicamentos (FDA) y la Oficina de Actividades Biotecnológicas (OBA) del Instituto Nacional de Salud(NIH). Los protocolos de terapia génica son revisados por el Comité Asesor de ADN Recombinante(RAC), organizado por OBA. La FDA y el RAC tienen funciones de revisión superpuestas, pero con distintas responsabilidades: tanto la FDA como el RAC consideran los protocolos preclínicos y clínicos. Sin embargo, RAC sirve como un foro abierto para examinar públicamente las inquietudes de la terapia génica que van más allá de la seguridad y la eficacia hasta la consideración de implicaciones éticas, legales y sociales(6).
La TG es una modalidad intrigante y tarde o temprano será parte de la atención estándar para una variedad de enfermedades. Existen preocupaciones genuinas con respecto a la seguridad de la transferencia de genes en humanos y los posibles efectos en la descendencia. Actualmente, la legislación solo permite la terapia génica en células somáticas(7).

\section{Métodos de Transferencia}

Un enfoque ex vivo implica la transducción de células en cultivo seguido por la inyección de estas células modificadas en el tejido diana. Las células modificadas genéticamente secretan la proteína deseada en el sitio de la inyección. Una ventaja de este enfoque es la posibilidad de utilizar vectores no virales. Aunque este método da como resultado una eficacia de transfección relativamente baja, se pueden seleccionar fácilmente células no transformadas. Además, las células pueden ser bien caracterizadas y expandidas antes del trasplante. Las células utilizadas para la terapia génica ex vivo deben ser fácilmente accesibles y capaces de sobrevivir durante períodos de tiempo más largos in vitro sin cambiar significativamente su fenotipo. Primaria, los cultivos celulares autólogos tienen un menor riesgo de transformación maligna y antigenicidad disminuida en comparación con las líneas celulares establecidas(8).

La primera administración de genes in vivo implica la inyección directa de vectores transgénicos, usualmente vıricos, en el tejido diana del huésped. La administración in vivo minimiza la manipulación de la población de células diana, dirigiendo directamente estas células en su entorno normal de huésped. A pesar de la naturaleza atractiva de la terapia in vivo, existen dos desventajas principales: eficiencia de transducción limitada y expresión transgénica transitoria. La eficiencia de transducción limitada resulta en gran medida de la inducción de una respuesta inmune del huésped contra el vector y las células infectadas. La expresión transitoria resulta de la incapacidad de la mayoría de los vectores para integrarse permanentemente en el genoma del huésped, dando lugar a una pérdida de expresión con sucesivas divisiones celulares(8). 
En otras vertientes terapéuticas tenemos por ejemplo la $\mathrm{TG}$ de células madre hematopoyéticas(HSC). Desde hace mucho tiempo, las HSC han sido un objetivo importante para la TG ex vivo. La modificación genética de las HSCs multipotentes garantizaría un suministro constante de su progenie corregida genéticamente en el cuerpo. Estas células tienen el potencial de tratar afecciones que se manifiestan cuando los linajes hematopoyéticos maduros no se desarrollan o funcionan correctamente. Dada la naturaleza de autorrenovación de las HSC y la necesidad de garantizar que las modificaciones genéticas se transmitan a su progenie, la corrección del gen debe introducirse de forma estable en la cromatina celular, ya sea mediante la inserción de transgenes mediada por vectores o mediante la edición de genes in situ(9).

Desarrollos recientes en técnicas de edición del genoma han proporcionado una opción para corregir las mutaciones en la línea germinal humana. En particular, CRISPR-Cas9 ((sistema agrupado de repetición palindrómica breve entremezclado e irregular (CRISPR) con Cas "CRISPR: proteína asociada) es una herramienta versátil para reconocer secuencias genómicas específicas e inducir DSB (roturas inducidas de doble cadena). A continuación, los DSB se resuelven mediante mecanismos de reparación de ADN endógenos, usando preferentemente una vía de unión de extremo no homóloga (NHEJ) siendo esta inapropiada para aplicaciones de corrección de genes porque introduce mutaciones adicionales en forma de inserciones o delecciones en el sitio de DSB, comúnmente denominadas indels. En algunos casos, sin embargo, las células diana activan una vía de reparación de ADN alternativa llamada reparación dirigida por homología (HDR) que reconstruye el sitio de DSB usando el cromosoma homólogo no mutante o una molécula de ADN exógeno suministrada como molde. Debido a que la eficiencia de HDR es relativamente baja, las aplicaciones de edición de genoma para la terapia génica han sido limitadas por el momento. (10)

Los sistemas CRISPR-Cas también se han modificado para un grupo diverso de aplicaciones. Como la recombiacion heterologa o fuera del objetivo es una preocupación para el
Cas9 de tipo salvaje, SpCas9 ha sido diseñado genéticamente por varios grupos según los datos de la estructura del cristal para aumentar su especificidad y disminuir la probabilidad de escisión fuera del objetivo(11).

\section{Terapia Genética y Cáncer}

El cáncer es una enfermedad genética con el crecimiento de células tumorales iniciadas por mutaciones que activan los controladores oncogénicos. Este proceso se combina con la activación o inactivación genética o no genética de genes que promueven o suprimen la proliferación de tumores. En muchos cánceres, la oncogénesis va acompañada de la acumulación de mutaciones, que pueden proporcionar una ventaja selectiva a las poblaciones de células cancerosas aumentando su grado de diversidad genética, acelerando su aptitud evolutiva. (12)

El enfoque terapéutico actual para el cáncer humano depende en gran medida de la interceptación de las vías de señalización que impulsan el crecimiento del cáncer. Sin embargo, tal enfoque invariablemente conduce a la tolerancia al fármaco y la resistencia al tratamiento farmacológico, ya que el genoma del cáncer ajusta sus patrones de expresión génica $y$, a través de nuevas mutaciones que evitan el bloqueo de señalización, desarrolla nuevas vías para apoyar el crecimiento. El enfoque del genoma puede tener ventajas sustanciales sobre la quimioterapia porque es específico para la secuencia del genoma del cáncer y mata las células cancerosas independientemente de si las mutaciones son cancerígenas. Es posible que nuevas mutaciones y genes de fusión se generen bajo la presión de la terapia del cáncer(13).

\section{Estrategias de terapéutica en oncogénetica terapéutica}

Se han esquematizado las posibilidades de blanco terapéuticos primordialmente con cuatro mecanismos potenciales.

Mutación de compensación: Se pretende corregir lesiones moleculares causales para transformación maligna. Quimioterapia molecular: Entrega o propagación selectiva de productos génicos tóxicos para el cáncer o células estromales tumorales, también entrega de 
secuencias citoprotectoras para mejorar la tolerancia tisular a citotóxicos potencialmente empleados.

Inmunopotenciación genética: Lograr inmunización activa contra antígenos asociados al tumor por transferencia genética ya sea en células tumores o componentes celulares del sistema inmune.

Oncolisis virus-mediada: Vectores virales con replicación condicional en células tumores ejerciendo oncolisis con efectos citopáticos directos(14).

La modulación de la respuesta inmune ante una neoplasia es una de las vertientes más prometedoras de las estrategias previo descritas, esto como en la inmunoterapia de células $\mathrm{T}$ por ejemplo con un número de ensayos clínicos crecientes relacionados a CAR (receptor antigenico quimérico). Notablemente, este enfoque agota no solo los clones malignos que causan enfermedades sino también casi todas las células B en el paciente. Aunque la falta de células B puede remediarse mediante la infusión de inmunoglobulinas, la depleción de otros linajes celulares podría no ser tan manejable(15).

La mayoria de ensayos que implementaron CARs dirigidos contra la molécula de superficie de células B CD19 reportaron beneficios dramáticos en pacientes con tumores malignos de células B, experimentando respuestas clínicas duraderas, incluida la remisión completa, con toxicidad principalmente manejable(16).

Hay iniciativas asociadas a las células madre neurales humanas aprovechando que son intrínsecamente trópicas al tumor, lo que les permite rastrear los sitios infiltrantes del tumor en el cerebro. Cuando se modifican para expresar un transgén terapéutico, las células madre neurales pueden servir como vehículos para la administración de fármacos localizados en tumores, evitando la barrera hematoencefálica para producir cantidades concentradas de quimioterapia directamente en los sitios del tumor y minimizando la toxicidad para el tejido cerebral normal(17).

El número de estudios abiertos en cáncer registrado está aumentando rápidamente; a diciembre de 2015, hay más de 200 protocolos con la inscripción de más de 8000 pacientes en todo el mundo. Aproximadamente el $40 \%$ de los protocolos abordan el uso de las células CAR T con la mayoría de los ensayos (85\%) que se realizan en los EE. UU. Y en China. Alrededor del $65 \%$ de los estudios están dirigidos contra tumores malignos hematológicos(18).

\section{TRATAMIENTO PARA SU USO CLÍNICO \\ APROBADO}

Dentro de los ejemplos de TG que tenemos disponible esta:

Talimogene laherperepvec (T-VEC) es un virus de herpes oncolítico modificado inyectable que se está desarrollando para el tratamiento del melanoma avanzado. Los estudios preclínicos han demostrado que T-VEC infecta preferentemente a las células de melanoma y ejerce actividad antitumoral a través de la muerte celular mediada directamente y mediante el aumento de respuestas inmunes locales e incluso distantes aprovechando que a menudo dicha neoplasia se disemina a sitios cutáneos o subcutáneos que son susceptibles de inyección directa intralesional(19).

El primer producto de terapia genética disponible comercialmente en China en 2003, Gendicine, también empleó un gen tipo salvaje p53 y lo administró a través de un adenovirus para tratar el carcinoma escamoso de cabeza y cuello(20). El principio de funcionamiento de tales terapias basadas en genes ha sido criticado por algunos estudios que demostraron que los genes funcionales p53 podrían estar presentes en algunos tumores y la replicación de Adv puede ser independiente del estado de p53(21).

El estado de p53 y su familia de genes podría regular la quimiosensibilidad de las células cancerosas a través de la senescencia y los efectos espectadores, que se define como la muerte o daño de las células que no recibieron quimioterapia o irradiación directamente, a través de la difusión de la muerte soluble factores de las células objetivo Al igual que la radioterapia, los principales efectos farmacológicos de los agentes quimioterapéuticos citotóxicos están destinados a dañar el ADN(22). 
También tenemos el ejemplo de Cerepro que es un vector adenoviral con el gen para la timidina quinasa del virus Herpes simplex (HSV-tk), desarrollado por Ark Therapeutics y destinado al tratamiento de tumores cerebrales malignos(23). Este funciona con el principio de virus oncolítico. HSV-tk es una denominada enzima activadora pro-fármaco que convierte el análogo de nucleótido Ganciclovir (GCV) en monofosfato de GCV. El GCV-monofosfato se convierte adicionalmente por células propias de quinasas en GCV-difosfato y finalmente en $\mathrm{su}$ metabolito tóxico GCV-trifosfato(24).

Aunque es necesario investigar más sobre el efecto de la exposición prolongada a $\mathrm{GcV}$ y la eficiencia de la eliminación tumoral con un bajo porcentaje de células HSV-TK presentes en el tumor para establecer la seguridad y la eficiencia de dicho tratamiento, la terapia génica suicida es un concepto muy prometedor. futuros estudios clínicos sobre el rabdomiosarcoma(25).

\section{CONCLUSIONES}

La terapia genética ha avanzado a lo largo de los años de manera vertiginosa con una cantidad considerable de ensayos clínicos conforme el conocimiento de nuevas técnicas facilitan el acceso a la modificación segura de la expresión genómica.

Es indudable que esta terapéutica ha llegado para quedarse y se vuelve relevante para el clínico y el investigador estar familiarizado sobre la misma principalmente si tiene una práctica con enfermedad oncológica.

Dentro de las estrategias de manejo específicamente en enfermedad oncológica tenemos a la mutación de compensación, quimioterapia molecular, inmunopotenciación genética y oncolisis virus-mediada todos sobre los cuales tenemos en la literatura registro de más de 10 ensayos clínicos cada uno de ellos varios con prometedores resultados.
1. Giacca M. Gene Therapy [Internet]. Milano: Springer Milan; 2010 [citado 21 de noviembre de 2017]. Disponible en:

http://link.springer.com/10.1007/97888-470-1643-9

2. Friedmann T. A brief history of gene therapy. Nat Genet. octubre de 1992;2(2):93-8.

3. Xiao-Jie L, Hui-Ying X, Zun-Ping K, Jin-Lian C, Li-Juan J. CRISPR-Cas9: a new and promising player in gene therapy. J Med Genet. mayo de 2015;52(5):289-96.

4. Li B, Gao N, Zhang Z, Chen Q, Li L, Li Y. Historical and Clinical Experiences of Gene Therapy for Solid Cancers in China. Genes. 24 de febrero de 2017;8(3):85.

5. Ginn SL, Alexander IE, Edelstein ML, Abedi MR, Wixon J. Gene therapy clinical trials worldwide to 2012 - an update: Gene therapy clinical trials worldwide to 2012 - an update. J Gene Med. febrero de 2013;15(2):65-77.

6. Husain SR, Han J, Au P, Shannon K, Puri RK. Gene therapy for cancer: regulatory considerations for approval. Cancer Gene Ther. diciembre de 2015;22(12):554-63.

7. Wirth T, Parker N, Ylä-Herttuala S. History of gene therapy. Gene. agosto de 2013;525(2):162-9.

8. Adriaansen J, Vervoordeldonk MJBM, Tak PP. Gene therapy as a therapeutic approach for the treatment of rheumatoid arthritis: innovative vectors and therapeutic genes. Rheumatology. 1 de junio de 2006;45(6):656-68.

\section{BIBLIOGRAFÍA}


9. Naldini L. Gene therapy returns to centre stage. Nature. 14 de octubre de 2015;526(7573):351-60.

10. Ma H, Marti-Gutierrez N, Park S-W, Wu J, Lee Y, Suzuki K, et al. Correction of a pathogenic gene mutation in human embryos. Nature. 2 de agosto de 2017;548(7668):413-9.

11. Jinek M, Jiang F, Taylor DW, Sternberg $\mathrm{SH}$, Kaya E, Ma E, et al. Structures of Cas9 Endonucleases Reveal RNA-Mediated Conformational Activation. Science. 14 de marzo de 2014;343(6176):1247997-1247997.

12. Chen DS, Mellman I. Elements of cancer immunity and the cancer-immune set point. Nature. 18 de enero de 2017;541(7637):321-30.

13. Chen Y, Gao D-Y, Huang L. In vivo delivery of miRNAs for cancer therapy: Challenges and strategies. Adv Drug Deliv Rev. enero de 2015;81:128-41.

14. Annan AC, Fisher PB, Dent P, Siegal GP, Curiel DT. Gene Therapy in the Treatment of Human Cancer. En: Coleman WB, Tsongalis GJ, editores. The Molecular Basis of Human Cancer [Internet]. New York, NY: Springer New York; 2017 [citado 16 de noviembre de 2017]. p. 811-41. Disponible en: http://link.springer.com/10.1007/978-1$\underline{59745-458-2 \quad 42}$

15. Maus MV, Fraietta JA, Levine BL, Kalos M, Zhao Y, June CH. Adoptive Immunotherapy for Cancer or Viruses. Annu Rev Immunol. 21 de marzo de 2014;32(1):189-225.

16. Kochenderfer JN, Dudley ME, Kassim $\mathrm{SH}$, Somerville RPT, Carpenter RO, Stetler-Stevenson M, et al. Chemotherapy-Refractory Diffuse Large B-Cell Lymphoma and Indolent B-Cell Malig- nancies Can Be Effectively Treated With Autologous T Cells Expressing an Anti-CD19 Chimeric Antigen Receptor. J Clin Oncol. 20 de febrero de 2015;33(6):540-9.

17. Portnow J, Synold TW, Badie B, Tirughana R, Lacey SF, D’Apuzzo M, et al. Neural Stem Cell-Based Anticancer Gene Therapy: A First-in-Human Study in Recurrent High-Grade Glioma Patients. Clin Cancer Res. 15 de junio de 2017;23(12):2951-60.

18. Almåsbak $\mathrm{H}$, Aarvak $\mathrm{T}$, Vemuri MC. CAR T Cell Therapy: A Game Changer in Cancer Treatment. J Immunol Res. 2016;2016:1-10.

19. Johnson DB, Puzanov I, Kelley MC. Talimogene laherparepvec (T-VEC) for the treatment of advanced melanoma. Immunotherapy. julio de 2015;7(6):6119.

20. Peng Z. Current Status of Gendicine in China: Recombinant Human Ad-p53 Agent for Treatment of Cancers. Hum Gene Ther. septiembre de 2005;16(9):1016-27.

21. Sakhawat A, Liu Y, Ma L, Muhammad T, Wang S, Zhang L, et al. Upregulation of Coxsackie Adenovirus Receptor Sensitizes Cisplatin-Resistant Lung Cancer Cells to CRAd-Induced Inhibition. J Cancer. 2017;8(8):1425-32.

22. Lu C, El-Deiry WS. Targeting p53 for enhanced radio- and chemo-sensitivity. Apoptosis. abril de 2009;14(4):597606.

23. Wirth T, Samaranayake H, Pikkarainen J, Määttä A-M, Ylä-Herttuala S. Clinical trials for glioblastoma multiforme using adenoviral vectors. Curr Opin Mol Ther. octubre de 2009;11(5):485-92. 
24. Moolten FL, Wells JM. Curability of tumors bearing herpes thymidine kinase genes transferred by retroviral vectors. J Natl Cancer Inst. 21 de febrero de 1990;82(4):297-300.

25. Konieczny P, Sułkowski M, Badyra B, Kijowski J, Majka M. Suicide gene therapy of rhabdomyosarcoma. Int J Oncol. febrero de 2017;50(2):597-605.

\section{CONFLICTO DE INTERÉS Y/O AGRADECIMIENTOS}

El autor declara que no existió ningún conflicto de interés en el presente reporte. 